\title{
National Institute of Environmental Health Sciences
}

National Cancer Institute

\section{Source}

National Cancer Institute. National Institute of Environmental Health Sciences. NCI

Thesaurus. Code C82610.

An institute within the National Institutes of Health with the mission to reduce the burden

of human illness and disability by understanding how the environment influences the development and progression of human disease. 